now essential that the great numbers of people beyond these circles be reached and involved, for it is these people who form the majority of the populations on the planet, and without them the building of a bright future cannot go ahead. In this respect there is a need for a steady, systematic programme of global education - a programme that is ongoing, dynamic, creative, and especially designed to reach the hearts and minds of the many millions of men and women in all regions and communities at the very grassroots of societies everywhere in the world.

The global education programme must be dedicated to translating the values for a better world - into understandable 'kernels'. These need to be concise, attractive, imaginative, and lively - designed not only to capture the interest of people, but also to motivate them to express their reactions in their daily lives and relationships. The phrase 'thinking globally, acting locally' must become much more widely understood and used than it is at present, the need being for the masses everywhere to practice what they hear preached (though of course having heard it!).

\section{The Programme of Global Education}

This must be conveyed through a world-wide communications network - a network linking up the channels of diverse organizations throughout the world - to ensure the simultaneous transmission of information to many thousands of organizations at local, national, regional, and international, levels, using all available means of communications and complemented by use of the media whenever possible.

The framework for this much-needed world-wide communications network is already being created: the New Computerized World Information Service (NCWIS) was launched at an international meeting of nongovernmental organizations in Geneva, Switzerland, in May 1989. The meeting was sponsored by the World Information Clearing Centre (WICC), also situated in Geneva.

The NCWIS is developing a global network of interactive communications combining computer link-ups with telex, telefax - and even postal systems where, at present, no other methods of communications are available. To 'humanize' the items of information (i.e. to make them widely understandable and interesting), visual presentations are used whenever possible. An International Advisory Panel (IAP), comprising scientists, humanists, and men of vision, is being created to provide guidance in elaborating 'humanized' information. The NCWIS provides a vehicle for a steady and systematic, global education programme. It is designed to bridge the gap between the visionary 'cloud' of theory for a better future and the consciousness of the world's people.

\section{World Information Clearing Centre Branches Needed World-wide}

To develop the NCWIS, regional branches of WICC are being established in all parts of the world. The regional WICC branches provide relay points for information exchange among participating organizations, and stimulate the development of improved communications concerning environmental matters everywhere. At the same time the WICC/NCWIS programme is dedicated to promoting goodwill and cooperation among people for building a better world. It is guided by the principles of the United Nations, and is developing cooperation with the specialized agencies of the United Nations inter alia to promote more effective dissemination of information on their activities than is currently available. WICC is linked with the United Nations International Computing Centre (UN ICC), Geneva.

The role of WICC Geneva is to assist nongovernmental organizations (NGOs) of all social and professional profiles to improve their communications' ${ }^{\prime}$ capacities concerning networking, technical equipment, and training matters - towards the widest and most effective dissemination and exchange of information among networks at local, national, regional, and international, levels and particularly to reach the grassroots of societies everywhere in the world. WICC is pleased to have the cooperation of the Hewlett-Packard Company (HP), whose assistance is provided both in Geneva and in all regions and countries where the NCWIS is being developed.

The NCWIS can make a contribution to saving the future of the planet. But its potential can be realized only with the active participation of men and women of goodwill - of scientists, humanists, visionaries, and spiritual and other leaders - together with representative organizations and scientific and educational institutions. Especially desirable are those who realize the need to close the 'gap' between the theory of a better future and the understanding of the role of the people in implementing it: without people's widest involvement, the theories and visions - even the most beautiful, inspiring, and valid ones - remain simply theories and visions.

SALly CURRY, Executive Secretary World Information Clearing Centre 14 Chemin Auguste-Vilbert 1218 Grand-Saconnex Geneva Switzerland.

\title{
Multidisciplinary Assessment of Environmental Risks for Human Health: Summer School in Italy
}

Once again this year the University of Siena is organizing a 2-weeks' long Summer School on this important theme, subtitled 'Contaminants in the Environment'. It will last from Monday 3 September until Saturday 15 September 1990, and the main topics will be:

- Distribution, levels, and fate.

- Comparative aspects of metabolism and toxicity.

- Detoxication strategies.

- Damage to biological structures.

- Pesticides and risks for human health.

Food, lodging, and travel expenses, will be provided for 15 Italian students; food, lodging, and part of their travel expenses, will be provided for 15 foreign students. A degree in Medicine or Biology is normally required of applicants, but holders of degrees in related fields may also be considered. The official language of the Summer School will be English.

If interested, please forward your application, curriculum vitae, list of publications, letter(s) of recommendation, and a brief abstract regarding one of the School topics (or of your personal research) for possible short presentation during the School, to:

\section{Professor Aristeo RenZONI Dipartimento di Biologia Ambientale Via delle Cerchia 3 53100 Siena, Italy.}

Telephone 0577-298831

Telefax 0577-298860

Telex 572459 UNIVSI I. 